\title{
Source \& Renewal - Adapting the Children's Literature into the Films and Television Plays
}

\author{
Xiao-ou Liu \\ Literature Department \& Fine Art Academy \\ NENU., 2555 Jingyue Rd., Changchun City, \\ Jilin Province, PRC. \\ 20485488@qq.com
}

\author{
Ying Hou \\ Literature Department \& Fine Art Academy \\ NENU., 2555 Jingyue Rd., Changchun City, \\ Jilin Province, PRC.
}

\begin{abstract}
With the advent of the digital media era, it has become increasingly common to produce films and TV plays from literature works. As a result, profound changes have taken place in the text reading and evaluation model. The process from text to screen is further defined as a reading and critical behavior In particular, it has had a tremendous impact on the adaptation of children's literary work to animated film and television, as well as related creation, dissemination, and acceptance. This article first reveal the interactive relationship between the two, analyzes the current situation and adaptation needs of children's literature into films, and then intensely discusses how Chinese animation should form more two-way interaction and cooperation with children's literature under "Image Age" and contemporary commercial atmosphere, which brings some suggestions for renewal.
\end{abstract}

\section{Keywords—Children's literature; Adaptation; Interaction}

\section{INTRODUCTION}

Since the 21st century, research on the serial relationship between textual products and visual products has attracted the attention of scholars both at home and abroad, and which has also opened up a new interdisciplinary perspective of the interactive development of literature and images. Namely, from the perspective of multidisciplinary blending, some scholars worked on analyzing the interaction between the literature and films \&televisions adaptation and strove for exploring the direction of development accompanied by the changes of the communication mechanism and means based on specific children's literary texts, film and television animated cultural phenomena.

\section{RESEARCH STATUS OF ANIMATION ADAPTATION OF CHILDREN'S LITERATURE}

\section{A. From the Perspective of History}

In the context of new media, the prosperity of literary film and television is in line with the characteristics of the time and the direction of development. There are several reasons among which two aspects must be mainly mentioned here: First, the innovation of production techniques and forms of communication provides a solid foundation for the development of images. Second, the accelerating pace of life and the changes of aesthetics of the time boost the people's reading habits shift from text to images [1].

However, the adaptation of children's literature into film and television animation in the fields of literature and video art are both small-scale perspectives, and their research content and achievements are not broad enough and mature.

First of all, domestic research on children's literary work and film and television adaptations basically focus on generalizing the amount of adaptations. In the case study of film and television adaptations, the majority of them take children's adapted film as subject. There is less research on film animation, adaptation strategies and methods.

Secondly, the research on the adaptation of film and television mostly stays on the stylistic level of technological development and the status of the current industry, and primarily crave for increased support and efforts to cultivate the original talents.

Thirdly, several studies simply put forward the inadequacies of lacking creative themes and content, rather than offer certain solutions. Few studies are able to clearly point out where to focus on and then how we can create more TV adaptations that have more touch of the mundane needs of children.

The unveiling of the digital media era is all the more potent in the context of filming the literary work. As is so often pointed out, the innovation of production techniques and forms of communication provides a solid foundation for the development of images. In addition, the accelerating pace of life and the changes of aesthetics of the time, drive the people's reading habits to shift from text to images. The consequent changes in the patterns of text reading and critical 
have also undergone profound changes. The process from text to screen has also been seen as a form of reading and criticism behavior, the development status of which is urgently needed to solve the problem of lagging theory.

\section{B. From the Perspectives of Aesthetic Essence and Educational Functions}

At present, the research on the aesthetic value of children's literature aesthetics and film and television animation are mainly independent. In the field of children's literature, texts are typically used as the object of study, and researches are conducted from the perspective of the target age. While the aesthetic study of film and television animation primarily based on the visual and aesthetic analysis of the image aesthetics. Experts and scholars also have different opinions and comments.

However, in terms of the deep analysis of art forms and the deep and wide scope of issues such as the change of aesthetic concepts, it has yet to be further discussed.

Some researches are conducted from the perspective of psychology and pedagogy, demonstrating the important role of childhood education in the development of human personality. In the isolated growing environment, children watching cartoons become a necessity for the growth process. Simultaneously, the audience completes the invisible education process.

According to statistics, current preschool children's imitation of the animation works is much higher than the parent's words and deeds. Some of them are based on the research of modern communication techniques, which point out that the animated film can effectively stimulate children's senses in a condensed manner in a relatively short period of time. Their unique forms of expression and moral ideals are quite popular and attract children most and have been part of the effective ways to implement children's moral education [2].

It is believed that film and television work is more interactive than a paper edition, which can receive direct feedback and are capable of following the work to visualize specific images and get certain pictures. This is impossible for paper children's literature.

Today's animated films have been an integral component of the movie market. In 2017, there was five animation in the top 10 global movie box office, which is enough to positively tell the profound social impact of the animated film. Most of the existing work and articles have been discussed from the perspective of children's education, and less concerned with the perspective of general education for all.

\section{From the Social Significance Perspective}

According to statistics, almost 70 percent of the film texts of Oscar-winning works have been adapted from various literary works.

In 2015, the American animated movie "Frozen" from Andersen's fairy tales created a world's $\$ 1.3$ billion box office and became the highest record of animated movies in history.

In 2017, Disney animated movie "Beauty and the Beast" which was also adapted from the fairy tales with its $\$ 1.3$ billion box office once again became a global winner. Examples of which adapted from the fairy tales abound among the classic animated film.

Then homegrown animation "Monkey King: Hero Is Back" based on mythical classics has created a box office of nearly one billion yuan, which has always been mentioned by our fellow citizens with zest.

The reason why this phenomenon out of expectation precisely unveils the bottleneck of the progress of the animated film and television adaptation of Chinese children's literature.

In 2016, more than 50 animated film was released at home, and more than 700,000 minutes of film and television cartoons were produced. Among these, sequels appeared in nearly half of the proportions. The "left over" became the mainstream, and the industry's desire for captivating plays has become a top priority to be solved.

As a matter of fact, the adaptation of children's literature to animate the film has also increased its influence and popularity. For instance, the thoroughly prevailing "Harry Potter" series has been nearly 10 times the circulation because of the release of the film. The "Pipyrus and Roussi" series of fairy tales have also been on the top-selling fairy tale list for 20 years owing to the animated film. This kind of backfeeding function provides strong support for the promotion of literary work.

\section{THE TECHNIQUES AND TACTICS OF THE ADAPTATION OF CHILDREN'S LITERARY WORK TO ANIMATED FILM AND TELEVISION}

\section{A. Focusing on Aesthetic Continuation}

The adaptation of film and television animation of children's literary work should be based on the premise of mutual creative characteristics and unique aesthetic values. Image and literary representation is two extremely different ways of telling, which accounts for these differences in the way they communicate and the different audience, and essentially similar aesthetic forms [3].

How to reconstruct and balance the multi-dimensionality of imagination and the relative designation of imagery in text stories of the animation film based on children's literary work in the process of recreating art from audiovisual art to audition art is important to note when adapting.

As an image art form, animation work is mostly based on imagery. With the premise of pursuing creativity and expressiveness, they stress the creation of style and creativity as well as small-scale expression methods and techniques [4]. From the story of the text to the motion pictures works, their core and aesthetic functions are of a common nature. Such work can have profound implications of both beauty and moral beauty, and should evoke children's aesthetic feelings while embodying the artistic beauty of alternative styles.

The recent media platform built by digital technology provides ample space for the adaptation of children's literature. Under the background of the media era, the adaptation should proceed through an analysis of discrepancy between the 
diversification of images and classical texts, the enrichment of thematic transmission and choices of disseminating expressiveness, along with the traceability and evolution of plots, and the description as well as reconstruction of characters, so as to investigate the children's literary animated adaptation strategies and solutions to seek the integration of children's literature and animation art.

\section{B. Focusing on the Value of Education}

Children's literature, film and television animation adapted from them all target children and adolescents as the main audience groups, and aims to express the nature of children. Then, both of which should be under the influence of the modern concept of children, with the premise of focusing on children's growth, giving children emotional resources, so as to stimulate children's love of life as the goal, this perception of life and love relay as an emotional education is most likely to resonate with children.

Meanwhile, certain attention must be given to help children and young people in shaping their positive outlook on life, independent world outlook, and correct values in the process of their development. This will also benefit for the educational function of children's growth, meaning of life, and ethical and moral construction [5]. While the difference and continuity between the adaptation of animation and original text in the educational value are also the content that needs attention in the adaptation.

Then how to achieve effective sublimation is the crucial point. Different types of film and television animation should have their own ways and methods of the convergence and effective fusion of the beauty of literature and education. The use of diverse artistic styles to find the balance between children's psychological and viewing needs is a direction of effort for all creators.

\section{Animated Adaptation is a Cultural Feedback for Children's Literature}

Abundant children's literary works provide animated film with many mature materials, laying a broad foundation for fostering strength and creativity. However, the adaptation of the truncation and tampering of the classic work also becomes an unavoidable wound, forming barriers to hinder the development of film and television.

In the movie field, animation art not only affects multilevel audiences, but also booms the issuance of books, feeds back traditional children's literature, opens up theoretical horizons for children's literature, updates academic speeches, and brings opportunities to pluralistic development of spatial language.

During the adaptation from children's literature to animation, we should take the era of multiculturalism and media integration in the new century as the background, based on film and television, and put the interactive relationship between the two in the broad aesthetic vision of culture.

From the point of view of creation and dissemination in different historical and cultural contexts, the literary works are deeply inspected, and the aesthetic methods, narrative strategies, expression techniques, ideologies, and education embodied in the adapted media works between different media ages and media forms are reflected. The similarities and differences in meaning and other aspects are tied to explicit analysis [6].

The creators should pay greater attention to the interactive relationship between contemporary children's literature and animation adaptation. They should guide children's literary writers to pay attention to the more abundant new media videos rather than the traditional paper literary texts, so as to put the traditional children's literature under a new era of visual media, and create more diverse developmental space.

At the same time, by drawing on the successful experience of the operation of foreign animation markets, and using the increasingly better domestic animation film operation market, it must be done to break through our thinking patterns, think out of the box, and consider how to effectively broaden the transformation extents of children's literary animated texts into coverage and intensification, organically integrate it quickly into the animation industry chain, improve domestic original animation capabilities, and transform concepts into a positive interaction between social and economic benefits.

In the 21 st century, an outlet for solving the potential crisis of Chinese culture is cultural ethnic self-confidence and multiple integration. China is a multi-ethnic country. The classic folk stories and children's literature on the one hand express the development of Chinese society and history.

On the other hand, it respects children as well as the future, and establishes a people-oriented aesthetic world among which relationships with adult society and children's society, different ethnic groups, and different regions in natural harmony.

Under the new media format, with the help of the film field, the study of the animated adaptation of children's literature is not only an exploration of the modern theories of film and television, but also a spiritual guide to the current mixed Chinese animation creation, an exploration of the arts of Chinese culture going global and contributing to humanity.

\section{ACKNOWLEDGEMENT}

This article is attached to "Research on Children' Literature of Visualization" which is a part of Jilin Provincial Department of Education "The Thirteenth Five-Year Plan" Social Science Research Project, the project number is 1605024

\section{REFERENCES}

[1] Qian, Wang The Invisible Barriers - Research on the Attribution of Children's Literature Disorders in the Mass Media Context. Beijing: China Social Sciences Press, 2013

[2] Xuyuan, Liu. Children's Literature Interpretation. [M] Beijing: Dolphin Press, 2012.

[3] John, M. Desmond. Peter. Hawkes. Translated by Shengsheng, Li. Adaption- Studying Film and Literature. [M] Beijing: World Publishing Cooperation, 2016.

[4] Bordwell. David, Kristin Thompson. Translated by Weixi, Zeng. Film Art: An Introduction. Beijing: Beijing Joint Publishing Company, 2015.

[5] Lothe, Jacob. Translated by Qiang, Xu. Narrative in Fiction and Film: An Introduction. [M] Beijing: Peking University Press, 2011.

[6] Ziqiang, Zhu. Research into Children's Literature in the Differentiating Period. [M] Guangxi: Jie Li Publishing House, 2013. 